\title{
Article
}

\section{Aging Mechanism of $\mathrm{Co}_{2} \mathrm{O}_{3}$-Doped $\mathrm{ZnO}$ Varistors ${ }^{\dagger}$}

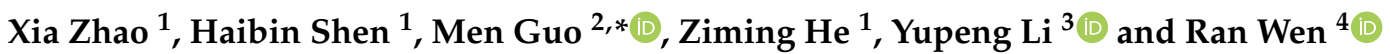 \\ 1 China Electric Power Research Institute, Beijing 100192, China; zhaoxia@epri.sgcc.com.cn (X.Z.); \\ shenhb@epri.sgcc.com.cn (H.S.); hezm@epri.sgcc.com.cn (Z.H.) \\ 2 State Key Laboratory of Electrical Insulation and Power Equipment, Xi'an Jiaotong University, \\ Xi'an 710049 , China \\ 3 State Key Laboratory of Power Transmission Equipment \& System Security and New Technology, \\ Chongqing University, Chongqing 400044, China; 201911021005@cqu.edu.cn \\ 4 School of Electronics and Information, Xian Polytechnic University, Xi'an 710048, China; \\ wenran1994@126.com \\ * Correspondence: guomen@stu.xjtu.edu.cn \\ + This paper is an extended version of our paper published in the 2020 IEEE International Conference on High \\ Voltage Engineering and Applications (ICHVE), Beijing, China, 6-10 September 2020.
}

\section{check for}

updates

Citation: Zhao, X.; Shen, H.; Guo, M.; He, Z.; Li, Y.; Wen, R. DC Aging Mechanism of $\mathrm{Co}_{2} \mathrm{O}_{3}$-Doped ZnO Varistors . Energies 2021, 14, 4011 https://doi.org/10.3390/en14134011

Academic Editor: Issouf Fofana

Received: 18 June 2021

Accepted: 1 July 2021

Published: 3 July 2021

Publisher's Note: MDPI stays neutral with regard to jurisdictional claims in published maps and institutional affiliations.

Copyright: (c) 2021 by the authors. Licensee MDPI, Basel, Switzerland. This article is an open access article distributed under the terms and conditions of the Creative Commons Attribution (CC BY) license (https:/ / creativecommons.org/licenses/by/ $4.0 /)$.
Abstract: Lowered power loss and asymmetrically electrical parameters are reported in the DC aging of $\mathrm{Co}_{2} \mathrm{O}_{3}$-doped $\mathrm{ZnO}$ varistors in this paper. Based on the frequency domain dielectric responses of the pristine and degraded samples, the present study explores the roles of point defects in the aging process via dielectric relaxations and their parameters. It is found that breakdown field increased more in the positive direction than the negative direction. Nonlinearity increased in the positive direction, whereas it decreased in the negative direction, and leakage current density increased more in the negative direction than the positive direction. Given the lowest migration energy of Zinc interstitial $\left(\mathrm{Zn}_{\mathrm{i}}, 0.57 \mathrm{eV}\right)$ and high oxygen ion conductivity in $\mathrm{Bi}_{2} \mathrm{O}_{3}$-rich phase, it is speculated that Zni and adsorbed oxygen $\left(\mathrm{O}_{\mathrm{ad}}\right)$ migrate under DC bias, and then change the defect structure and the double Schottky barrier (DSB) at grain boundaries. As a result, the forward-biased barrier height gradually decreases more than the reverse-biased one.

Keywords: ZnO varistors; DC aging; double Schottky barrier; point defects

\section{Introduction}

$\mathrm{ZnO}$ varistor, one of the polycrystalline semiconductors, manifests excellently nonohmic current-voltage $(I-V)$ characteristics so that they are vastly used for overvoltage protection in the electrical system [1]. Recently, as high voltage direct current power transmission develops rapidly, $\mathrm{ZnO}$ varistors are available to a very high voltage level of $\pm 1100 \mathrm{kV}$ on the transmission line and at the converter station. In these applications, the $\mathrm{ZnO}$ blocks are continuously stressed by pure DC or a dominant DC component with superimposed continuous (high frequency) transients, and ion migrations in $\mathrm{ZnO}$ varistors are more serious. Therefore, the aging under DC loading was significantly different compared to the AC world. Most of the available blocks were stable under AC but not necessarily stable under a DC stress. For low-voltage $\mathrm{ZnO}$ varistors, simulations are developing to describe the DC current-voltage $(I-V)$ behavior and to obtain extended DC $I-V$ characteristics in the time domain $[2,3]$.

The DSB is generally accepted to explain the non-ohmic characteristics of $\mathrm{ZnO}$ varistor, which is also employed to analyze its aging phenomena [4-7]. At an early stage, Eda and Matsuoka studied the influence of DC-biased stress on $\mathrm{ZnO}$ varistors by thermally stimulated current, where they suggested that the aging arose from migration of ions in the depletion layer [8]. Gupta and Carlson further pointed out that the migration was relevant to zinc interstitial $\left(\mathrm{Zn}_{\mathrm{i}}\right)$ under electrical-thermal driving force [9]. Via positron annihilation spectroscopy, Ramanachalam et al. [10] unveiled that positron trap density decreased with 
DC stress increasing and associated positron lifetime increased, which was attributed to recombination of zinc interstitial migrating to grain boundary with zinc vacancy, leading to lower barrier height. Besides DC operation voltage, conductivity at contact points between varistor granules may also be increased due to accumulated damage from Joule heating by multiple high voltage strokes [11].

Besides ion migration, some other interesting experimental results were also reported. Ohbuchi et al. [12] analyzed the impact of AC aging on the interface states of $\mathrm{ZnO}$ varistors by deep level transient spectroscopy and found that aging phenomena were highly referring to the emission rate of the interface states, which they claimed arose from migration of adsorbed oxygen ion $\left(\mathrm{O}_{\mathrm{ad}}\right)$. Takahashi et al. [13] found that oxygen atmosphere could inhibit the leakage current during the aging process and resume aged samples. Ramirez et al. argued that it was due to the adsorption of oxygen influenced by $\beta / \delta-\mathrm{Bi}_{2} \mathrm{O}_{3}$ at grain boundaries and then the control of barrier [14]. Mielcarek et al. [15] also investigated the influence of $\beta / \delta-\mathrm{Bi}_{2} \mathrm{O}_{3}$ phases on aging phenomena.

Cobalt oxide is one of the commonly used dopants to modify the DSBs at grain boundaries. Cobalt ions in $\mathrm{ZnO}$ grains exit as $\mathrm{Co}^{2+}$, which replaces $\mathrm{Zn}$ at the lattice sites in the manner of tetrahedral coordination [16]. $\mathrm{Co}_{2} \mathrm{O}_{3}$ can increase the oxygen partial pressure in the sintering processing and decrease the density of donor, which decreases the conductivity of the $\mathrm{ZnO}$ grains [17]. Co was conducive to forming interface states between the conduction band and the valence band of $\mathrm{ZnO}$ [18]. Except for changing multi-scale defect structure, the phase of $\mathrm{Bi}_{2} \mathrm{O}_{3}$ can also be influenced by $\mathrm{Co}_{2} \mathrm{O}_{3}$ [19]. In a word, studies on $\mathrm{Co}_{2} \mathrm{O}_{3}$-doped $\mathrm{ZnO}$ varistors have been mainly focused on reducing grain boundary resistivity, enhancing the nonlinearity, preventing $\mathrm{Bi}_{2} \mathrm{O}_{3}$ evaporation, and improving stability against $\mathrm{AC}$ aging. However, the effect of $\mathrm{Co}_{2} \mathrm{O}_{3}$ dopant on the stability of $\mathrm{ZnO}$ varistors against DC aging has not been systematically presented yet. It is also helpful to understand DC aging mechanism based on $\mathrm{Co}_{2} \mathrm{O}_{3}$-doped $\mathrm{ZnO}$ varistors due to its obvious modification effect on the defect structure.

In this paper, the $\mathrm{I}-\mathrm{V}$ characteristics of $\mathrm{Co}_{2} \mathrm{O}_{3}$-doped $\mathrm{ZnO}$ varistors in low-current (prebreakdown) region were measured before and after DC aging. Power loss was continuously recorded during DC aging. Broadband dielectric spectroscopy was utilized to analyze relaxation processes, by which the variation of defects due to aging was compared. Finally, dynamics of ion migrations during DC aging was deduced, of which the effect on the DSB was also analyzed.

\section{Experiment}

A series of $\mathrm{ZnO}$ varistor block samples were prepared via the solid-state reaction method. Besides $(95-x) \mathrm{mol} \% \mathrm{ZnO}$, raw materials contained approximately $1 \mathrm{~mol} \%$ $\mathrm{Bi}_{2} \mathrm{O}_{3}, 1 \mathrm{~mol} \% \mathrm{Sb}_{2} \mathrm{O}_{3}, 0.5 \mathrm{~mol} \% \mathrm{MnCO}_{3}, 1 \mathrm{~mol} \% \mathrm{NiO}$, and $1.5 \mathrm{~mol} \% \mathrm{SiO}_{2}$ (mainly for inhibiting grain growth). The content of $\mathrm{Co}_{2} \mathrm{O}_{3}$ was chosen as $x=0,0.28,0.55,0.83,1.1$, and $1.38 \mathrm{~mol} \%$. The raw materials were mixed by a $12 \mathrm{~h}$ ball-milling with deionized water and an appropriate amount of polyvinyl alcohol (PVA). Next, the slurries were processed into particles with a size of $80 \sim 120 \mu \mathrm{m}$ via spray granulation. The particles were added $3 \mathrm{wt} \%$ water to be stale for $24 \mathrm{~h}$ and then were pressed into pellets under $100 \mathrm{MPa}$ for $10 \mathrm{~s}$. The pellets were pre-sintered at $600{ }^{\circ} \mathrm{C}$ to discharge PVA. Finally, the pellets were sintered in air at $1150{ }^{\circ} \mathrm{C}$ for $2 \mathrm{~h}$, and naturally cooled. All samples were designated as S1, S2, S3, $\mathrm{S} 4$, S5, and S6 for short, with increasing $\mathrm{Co}_{2} \mathrm{O}_{3}$ content. Based on Archimedes principle of water displacement, densities and porosities were measured for all samples.

After polishing both sides of the samples, Al electrodes were sputtered for electrical measurements. The nonlinear coefficient $\alpha=1 / \lg \left(E_{\mathrm{B}} / E_{\mathrm{A}}\right)$ was calculated from the current density-electric field $(J-E)$ curves, where $E_{\mathrm{A}}$ and $E_{\mathrm{B}}$ (called breakdown field) is an electric field under $0.1 \mathrm{mAcm}^{-2}$ and $1 \mathrm{mAcm}^{-2}$, respectively. The leakage current density $\left(J_{\mathrm{L}}\right)$ was acquired at $0.75 E_{\mathrm{B}}$. These varistors were heated at $135{ }^{\circ} \mathrm{C}$ and applied an electric field of $0.9 E_{\mathrm{B}}$ for more than $160 \mathrm{~h}$. The direction, the same as that of the electric field during aging, was referred to as the positive direction, and the opposite direction is the 
negative direction. After aging $J-E$ curves of both directions were taken into consideration. Dielectric properties were measured by an impedance analyzer (Novocontrol, Concept 80 , Montabaur, Germany) in a frequency range of $10^{-1} \sim 10^{6} \mathrm{~Hz}$ and a temperature range of $-110 \sim 200{ }^{\circ} \mathrm{C}$.

\section{Results and Discussion}

\subsection{Macro Electrical Properties}

Phase compositions and microstructures of all samples have been presented elsewhere [19]. $\alpha-\mathrm{Bi}_{2} \mathrm{O}_{3}$ phase was detected in samples $\mathrm{S} 1-\mathrm{S} 4$, whereas $\delta-\mathrm{Bi}_{2} \mathrm{O}_{3}$ phase was detected in samples $\mathrm{S} 5$ and $\mathrm{S} 6 . \delta-\mathrm{Bi}_{2} \mathrm{O}_{3}$ phase trended to appear in those samples with higher $\mathrm{Co}_{2} \mathrm{O}_{3}$ content. Spine phase $\mathrm{Zn}\left(\mathrm{Zn}_{4 / 3} \mathrm{Sb}_{2 / 3}\right) \mathrm{O}_{4}$ was identified in $\mathrm{S} 1-\mathrm{S} 3$, and spine phase $\mathrm{Co}\left(\mathrm{Co}_{4 / 3} \mathrm{Sb}_{2 / 3}\right) \mathrm{O}_{4}$ was identified in S4-S6. Average grain sizes $(\lambda)$, densities $(D)$, and porosities $(H)$ are shown in Table 1 . $\lambda$ changed little with increasing $\mathrm{Co}_{2} \mathrm{O}_{3}$ content. $D$ decreased at low contents, and then increased with increasing $\mathrm{Co}_{2} \mathrm{O}_{3}$ content. Changes of $H$ were opposite to $D$. It was found that microstructures changed little after doping $\mathrm{Co}_{2} \mathrm{O}_{3}$.

Table 1. Average grain sizes $(\lambda)$, densities $(D)$, and porosities $(P)$ of $\mathrm{Co}_{2} \mathrm{O}_{3}$-doped $\mathrm{ZnO}$ varistors.

\begin{tabular}{cccc}
\hline No. & $\boldsymbol{\lambda}(\boldsymbol{\mu \mathbf { m } )}$ & $\boldsymbol{D}\left(\mathrm{gcm}^{-\mathbf{3}}\right)$ & $\boldsymbol{H} \mathbf{( \% )}$ \\
\hline S1 & 9.98 & 5.32 & 0.016 \\
S2 & 10.27 & 5.25 & 0.018 \\
S3 & 10.85 & 5.28 & 0.024 \\
S4 & 10.19 & 5.23 & 0.051 \\
S5 & 10.24 & 5.23 & 0.020 \\
S6 & 10.71 & 5.42 & 0.021 \\
\hline
\end{tabular}

Electrical properties of these as-sintered varistors were reported elsewhere. During DC aging, power loss $(P)$ was continuously recorded, as shown in Figure $1 . P_{0}$ is a maximum of $P$ at the beginning of aging. $P$ rapidly decreases in the initial time. Ion migrations were most intense when DC voltage was applied. With increasing aging time, equilibrium was established between migrations and diffusions. Thus, $P$ gradually decreased. Approximately after $20 \mathrm{~h}, P$ of S5 gradually increases, whereas those of others decrease with lower rates than before. This indicates that these samples except $\mathrm{S} 5$ are stable under the DC aging test. As to S5, the increase of $P$ is due to $\delta-\mathrm{Bi}_{2} \mathrm{O}_{3}$, which is a phase of $\mathrm{Bi}_{2} \mathrm{O}_{3}$ with the highest conductivity of oxygen ion. During aging, adsorbed oxygen can desorb and easily escape from the varistor through $\delta-\mathrm{Bi}_{2} \mathrm{O}_{3}$ [20]. As a result, the interface states and Schottky barrier height decrease, and $P$ gradually increases due to increasing leakage current. Leakage current density $\left(J_{\mathrm{L}}\right)$ vs. aging time $(t)$ satisfies

$$
J_{\mathrm{L}}=J_{\mathrm{L} 0}+K_{\mathrm{T}} \sqrt{t},
$$

where $J_{\mathrm{L} 0}$ is the leakage current density at $t=0 ; K_{\mathrm{T}}$ is the degradation rate. $J_{\mathrm{L}}$ of $\mathrm{S} 5$ was extrapolated via Equation (1), where it would be equal to the initial value after $1489 \mathrm{~h}$, with $J_{\mathrm{L} 0}=53.04 \mu \mathrm{A}$ and $K_{\mathrm{T}}=1.45 \mu \mathrm{A} \cdot \mathrm{cm}^{-2} \cdot \mathrm{h}^{0.5}$.

As an example, $J-E$ curves of $S 1$ are shown in Figure 2. After DC aging, J-E curves became asymmetric in both positive direction and negative direction. Leakage currents increased in both directions, where the increase is more in the negative direction. Breakdown field also increased in both directions, where the increase is more in the positive direction. All electrical parameters of S1-S6 before and after DC aging are shown in Figure 3. Breakdown field increased more in the positive direction than the negative direction, nonlinearity increased in the positive direction, whereas it decreased in the negative direction. Leakage current density increased more in the negative direction than the positive direction. It is found that after DC aging, electrical properties degraded more seriously in the negative direction. 


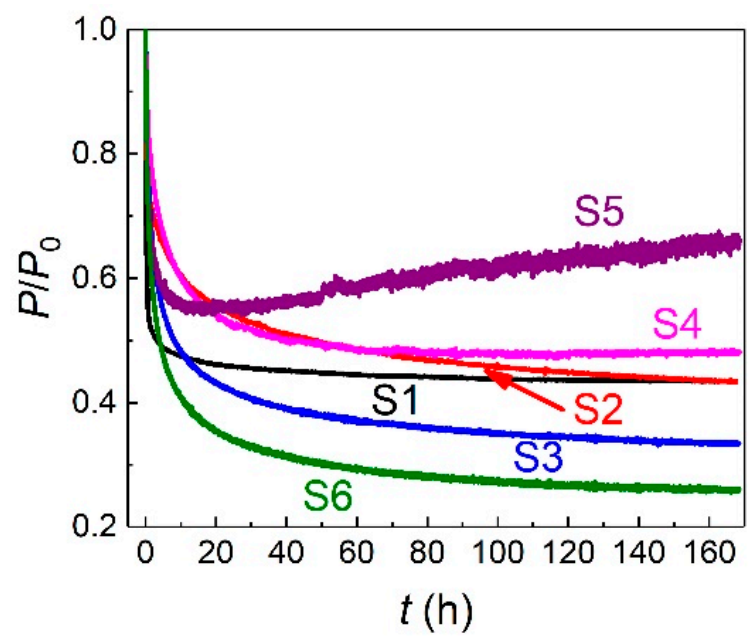

Figure 1. Power losses of S1-S6 during DC aging. Aging condition: Heated at $135^{\circ} \mathrm{C}$ and applied an electric field of $0.9 E_{\mathrm{B}}$ for more than $160 \mathrm{~h}$, where $E_{\mathrm{B}}$ is the electric field when current density is $1 \mathrm{mAcm}^{-2}$ and is called breakdown field.

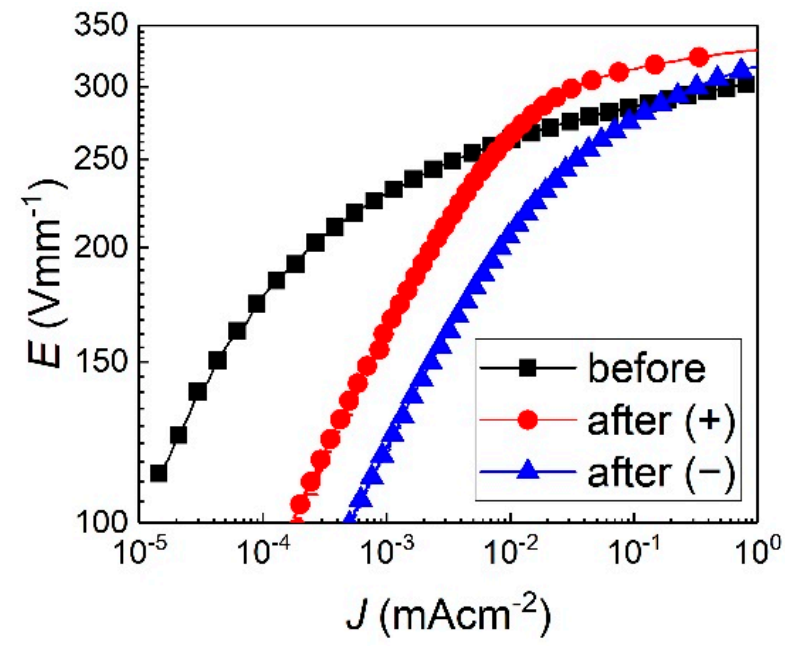

Figure 2. J-E characteristics of S1 before and after DC aging.

(a)
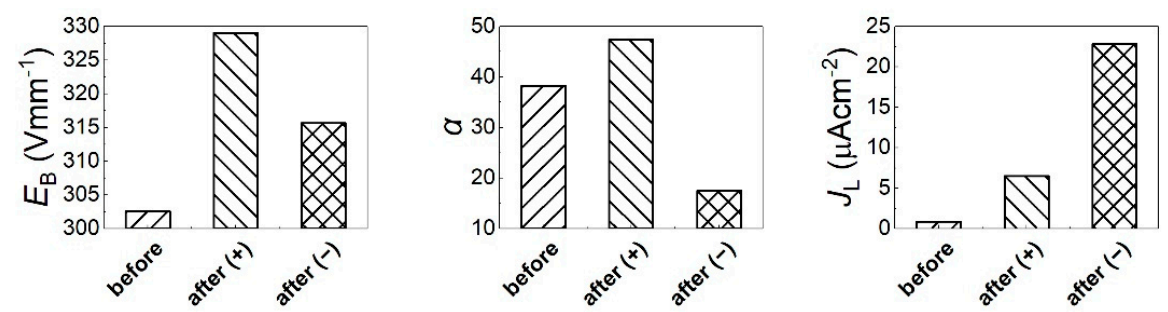

Figure 3. Cont. 
(b)
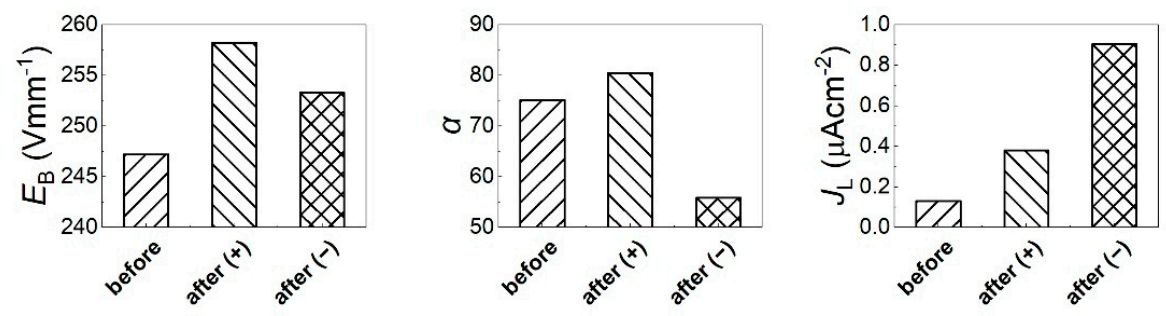

(c)
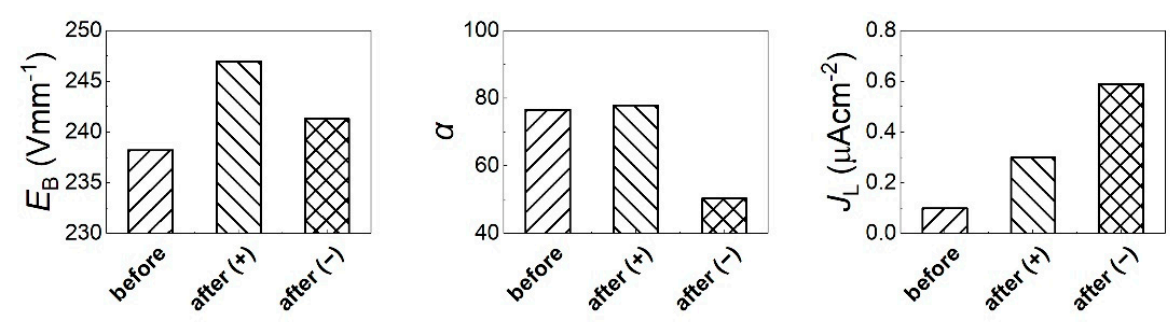

(c)
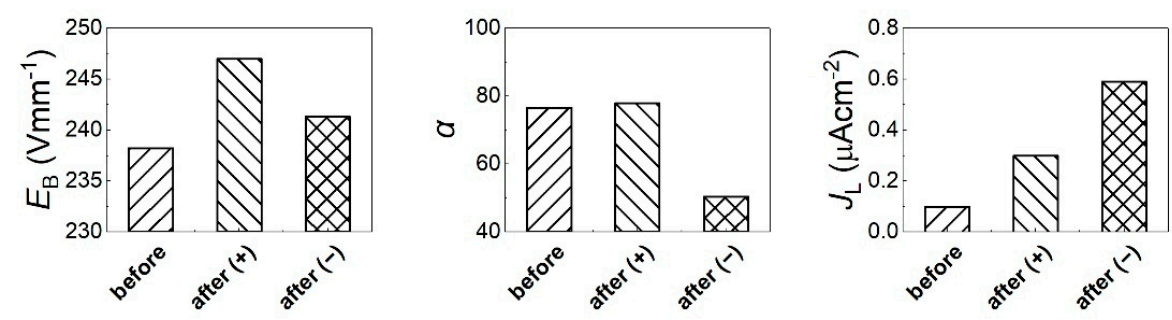

(d)
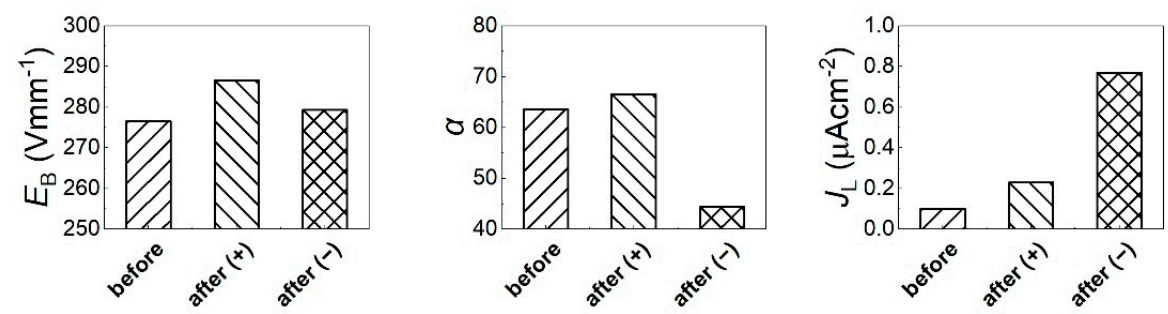

(e)
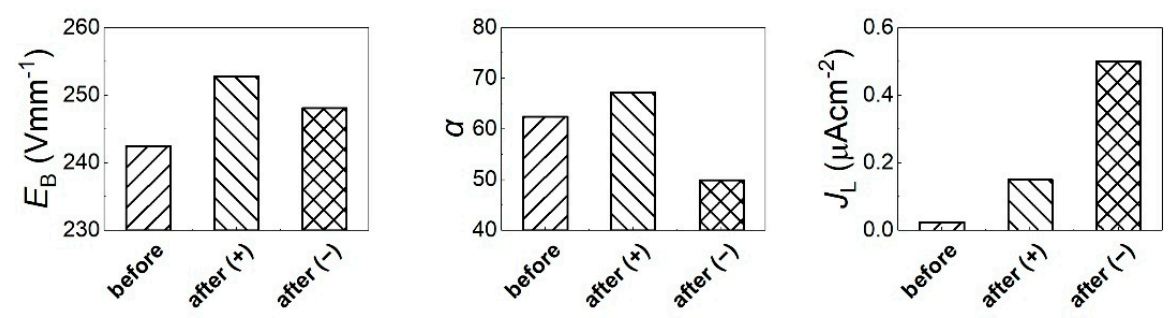

Figure 3. Cont. 
(f)

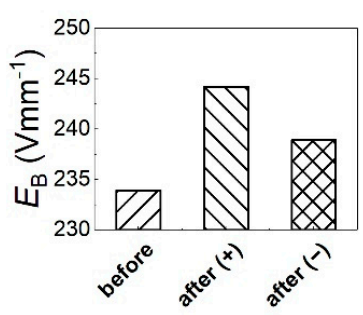

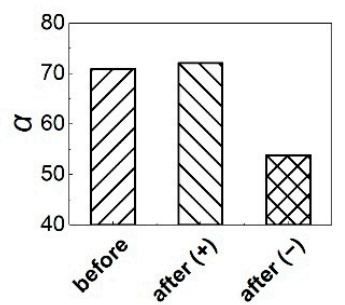

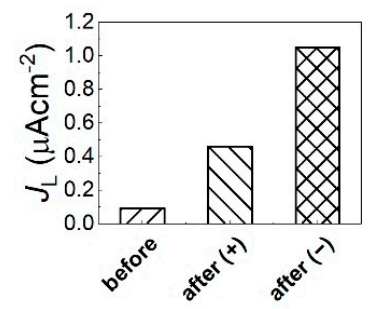

Figure 3. Electrical parameters of S1-S6 before and after DC aging (a-f) S1-S6.

The nonlinear coefficient $\alpha=1 / \lg \left(E_{\mathrm{B}} / E_{\mathrm{A}}\right)$ was calculated from the current densityelectric field $(J-E)$ curves, where $E_{\mathrm{A}}$ and $E_{\mathrm{B}}$ (called breakdown field) are electric fields under $0.1 \mathrm{mAcm}^{-2}$ and $1 \mathrm{mAcm}^{-2}$, respectively. The leakage current density $\left(J_{\mathrm{L}}\right)$ was acquired at $0.75 E_{\mathrm{B}}$.

\subsection{Dielectric Response}

Relaxations of intrinsic point defects of $Z n_{i}$ and oxygen vacancy $\left(V_{O}\right)$ can be detected at lower temperatures. $\mathrm{Zn}_{\mathrm{i}}$ is the most mobile ion in $\mathrm{ZnO}$ varistors and plays a decisive role in aging. Relaxations of extrinsic defects respond at higher temperatures. Extrinsic defects, such as grain boundaries and intergranular phases, may be changed due to temperature rise, for example, partial melting arose from intensive heat generated in the varistors when high currents flow [21]. These defects decide the property of DSB.

As an example, dielectric responses of $\mathrm{S} 1$ at $-100^{\circ} \mathrm{C}$ and $200^{\circ} \mathrm{C}$ before $\mathrm{DC}$ aging are presented to analyze these defects, which is shown in Figure 4 . Two obvious loss peaks were manifested in $\varepsilon^{\prime \prime}$ spectroscopy at $-100{ }^{\circ} \mathrm{C}$ in Figure 3 a, while only a vague one at $200{ }^{\circ} \mathrm{C}$ in Figure $3 \mathrm{~b}$ was detected. Frequency has effects on the electrical characteristics of varistors [22]. The reason is that DC conductivity exponentially increased at higher temperatures, which masked loss peak(s) at low frequencies. Here, frequencies lower than $10 \mathrm{~Hz}$ are referred to as low frequencies. Compared to Figure 2, the dielectric responses for the pristine sample had little difference. Note that some relaxation peaks were hidden by DC conductivity at high temperatures, a derivative method was applied to characterize relaxation processes $[23,24]$. It was found that five relaxations exist in a temperature range of $-110 \sim 200{ }^{\circ} \mathrm{C}$ and a frequency range of $10^{-1} \sim 10^{6} \mathrm{~Hz}$. At low temperatures $\left(-110 \sim-60^{\circ} \mathrm{C}\right)$, two loss peaks were detectable, which were designated as Peak $A$ and Peak B. At high temperatures $\left(150 \sim 200^{\circ} \mathrm{C}\right)$, two loss peaks were also characterized that were designated as Peak $C$ and Peak D. Because Peak E had not completely manifested in the spectra, it is not discussed in the following content.

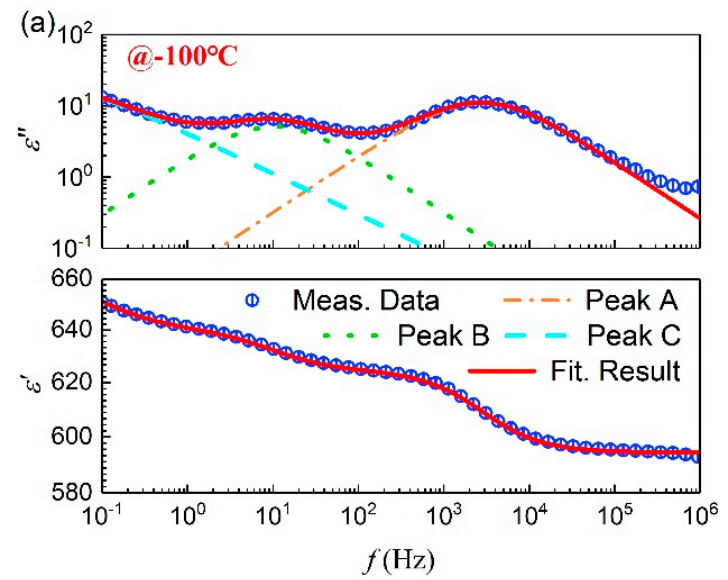

Figure 4. Cont. 


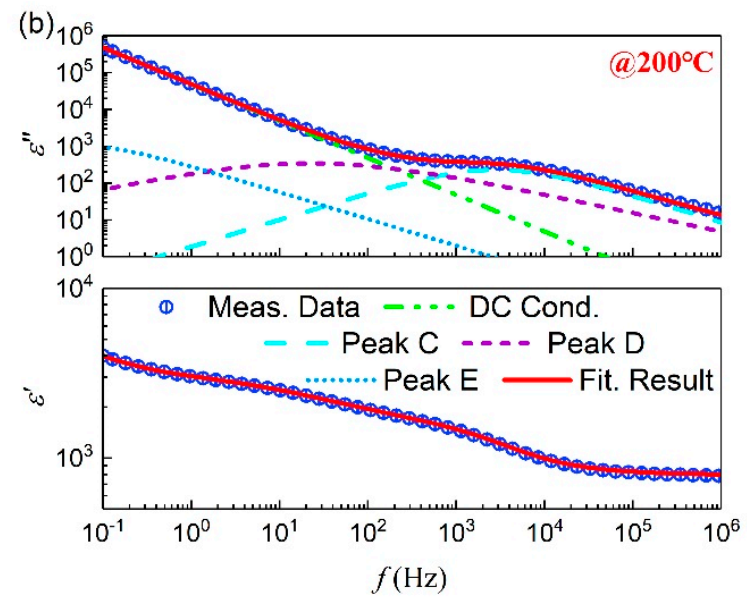

Figure 4. Dielectric responses of S1 before DC aging (a) $-100^{\circ} \mathrm{C}(\mathbf{b}) 200^{\circ} \mathrm{C}$.

To obtain parameters of all loss peaks and DC conductivity, Cole-Cole model was applied to fit the complex permittivity [25]:

$$
\varepsilon^{*}=\varepsilon_{\infty}+\frac{\sigma_{\mathrm{dc}}}{j \omega \varepsilon_{0}}+\sum_{i} \frac{\Delta \varepsilon_{i}}{1+\left(j \omega \tau_{i}\right)^{1-\alpha_{i}}}
$$

In this expression, $\varepsilon^{*}=\varepsilon^{\prime}-j \varepsilon^{\prime \prime}$ is the complex permittivity, $\varepsilon_{\infty}$ the limiting highfrequency permittivity, $\omega$ the angular frequency, $\sigma_{\mathrm{dc}}$ the dc conductivity, $\varepsilon_{0}$ the vacuum permittivity, $\Delta \varepsilon_{i}$ and $\tau_{i}$ the relaxation amplitude and the relaxation time for the $i$ th relaxation, respectively, $\alpha_{i}$ the shape (or relaxation time distribution) parameters.

The genetic algorithm was used to fit measurement results. For results at lower temperatures, all parameters were obtained based on $\varepsilon^{\prime \prime}$, and examined over $\varepsilon^{\prime}$. For results at higher temperatures, $\sigma_{\mathrm{dc}}$ was firstly calculated via $\varepsilon^{\prime \prime}$ at the low frequencies. Relaxation parameters were obtained from $\varepsilon^{\prime}$. Then, all parameters were examined by $\varepsilon^{\prime \prime}$. Frequency ranges of 'steps' in $\varepsilon^{\prime}$ spectra or loss peaks in $\varepsilon^{\prime}$ spectra were obtained in advance for globally optimal solutions. All parameters of loss peaks of S1-S6 before and after DC aging are shown in Figure 5. Peak $A$ and Peak B were ascribed to the relaxation of $Z_{n}{ }^{\bullet \bullet}$ and $\mathrm{V}_{\mathrm{O}}{ }^{\bullet}$ in depletion layers [26]. After DC aging, $\Delta \varepsilon_{i}$ and $\alpha_{i}$ of the two peaks changed a bit. This is because of the change of defect distribution in depletions. $\tau_{i}$ of Peak $A$ and Peak $B$ almost did not change due to the intrinsic nature of the two defects. Peak $C$ and Peak D were related to extrinsic defects, where Peak $C$ was caused by inter-granular phase and Peak $D$ is speculated due to the interface states $[27,28]$. Zhao et al. recently found that Peak $C$ was related to both $\mathrm{Bi}_{2} \mathrm{O}_{3}$-rich phase and the spinel phase, and was therefore, due to relaxation of interface between the two phases [24]. Because of the extrinsic nature of the two defects, all parameters of Peak $C$ and Peak D change to some extent.

(a)

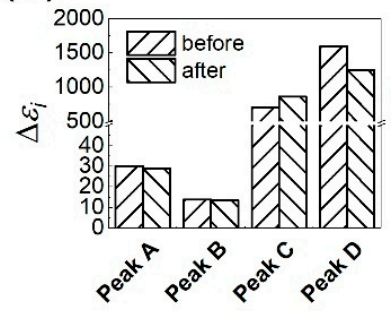

Figure 5. Cont.
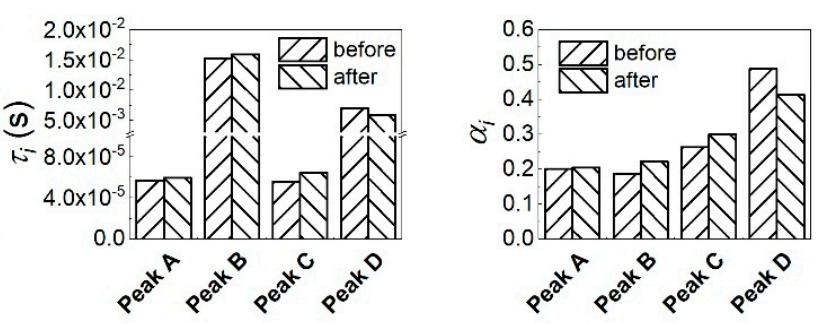
(b)
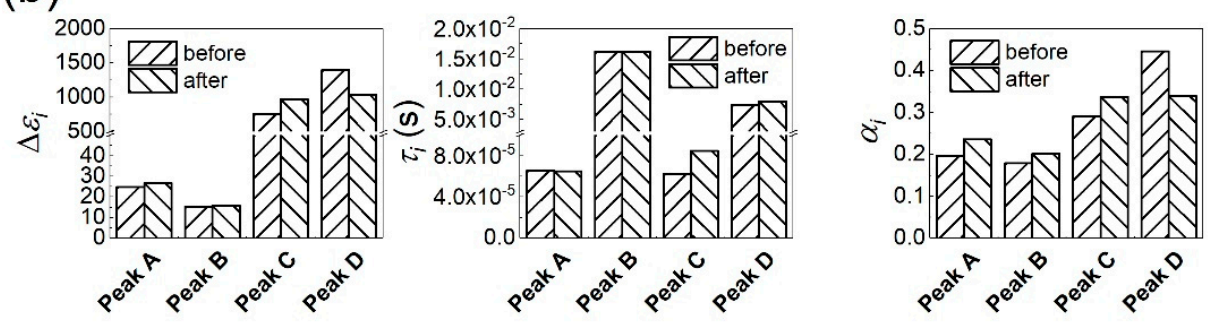

(c)
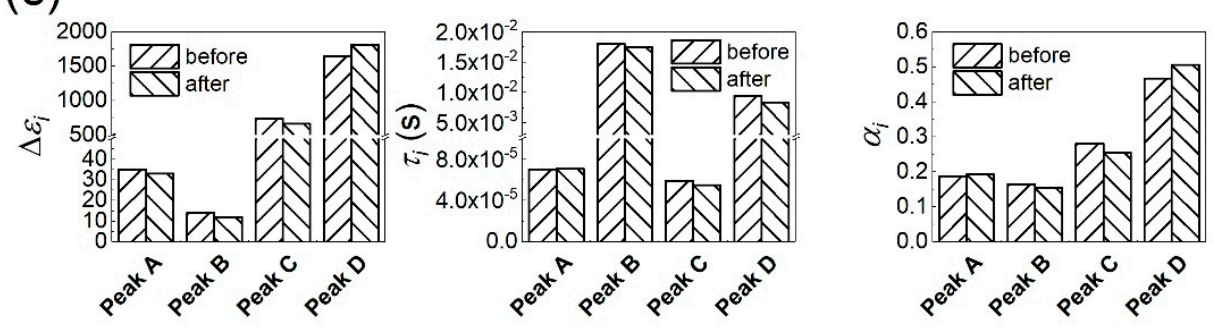

(d)
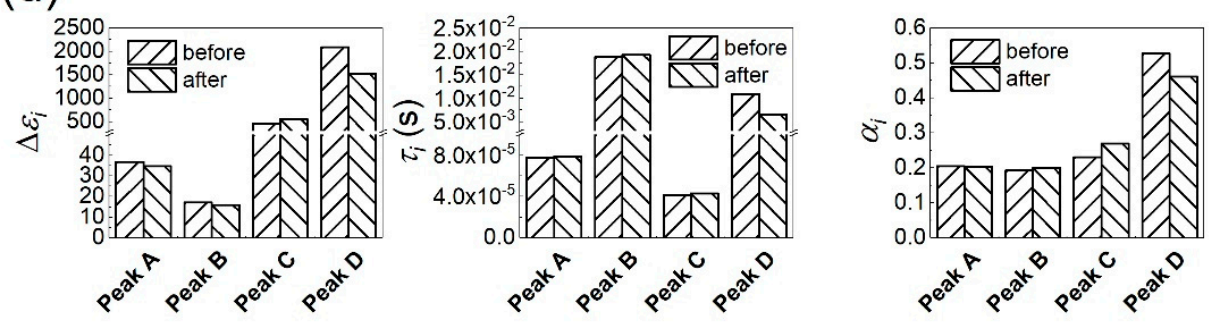

(e)
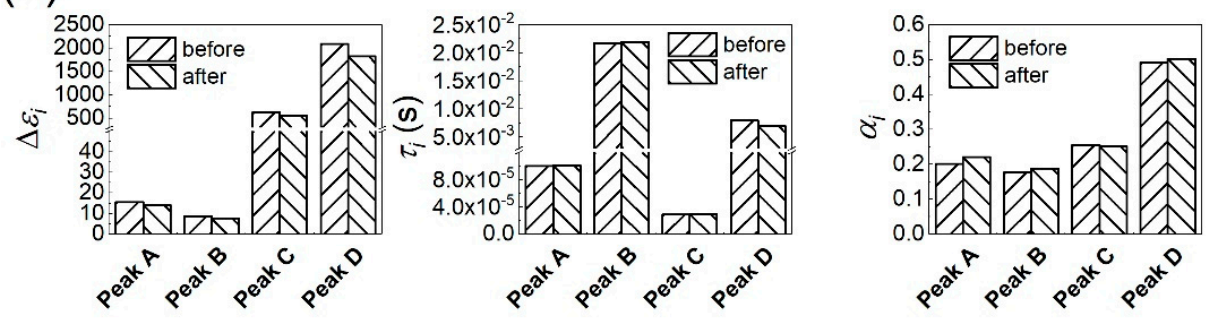

(f)
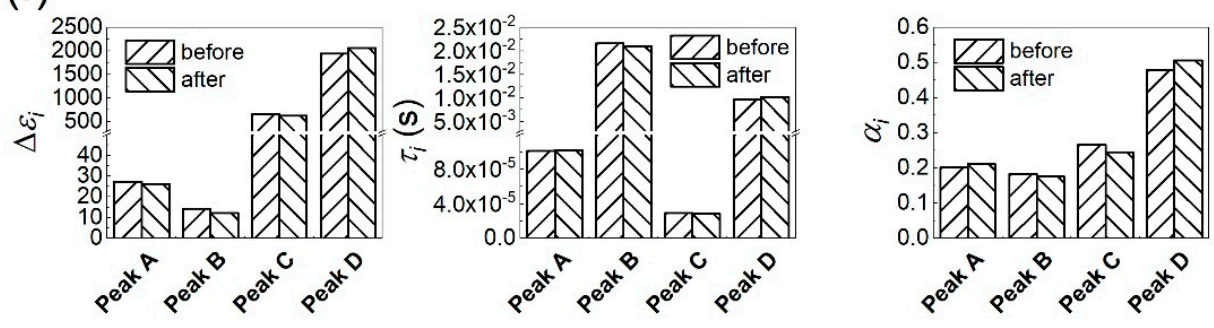

Figure 5. Parameters of all loss peaks before and after DC aging (a-f) S1-S6.

DC conductivities $\left(\sigma_{\mathrm{dc}}\right)$ were obtained from $\sigma^{\prime}$ spectra at $0.1 \mathrm{~Hz}$, which was also calculated via dielectric responses at higher temperatures. $\sigma_{\mathrm{dc}}$ of $\mathrm{S} 1-\mathrm{S} 6$ at $200{ }^{\circ} \mathrm{C}$ before and after DC aging are shown in Figure $6 \mathrm{a}$. After DC aging, $\sigma_{\mathrm{dc}}$ increases for every sample. As $\sigma_{\mathrm{dc}}$ was obtained from frequency-domain conductivity at the lowest measurement 
frequency, it reflects the property of the DSB $[29,30]$. Based on the Arrhenius equation, activation energies $\left(E_{\mathrm{dc}}\right)$ of $\sigma_{\mathrm{dc}}$ were also calculated, as shown in Figure $6 \mathrm{~b}$. It is found that $E_{\mathrm{dc}}$ decreases for all samples after DC aging. Therefore, the reason why $\sigma_{\mathrm{dc}}$ increases is mainly because $E_{\mathrm{dc}}$ decreases, and the decrease of $E_{\mathrm{dc}}$ is due to the aging of the DSB.
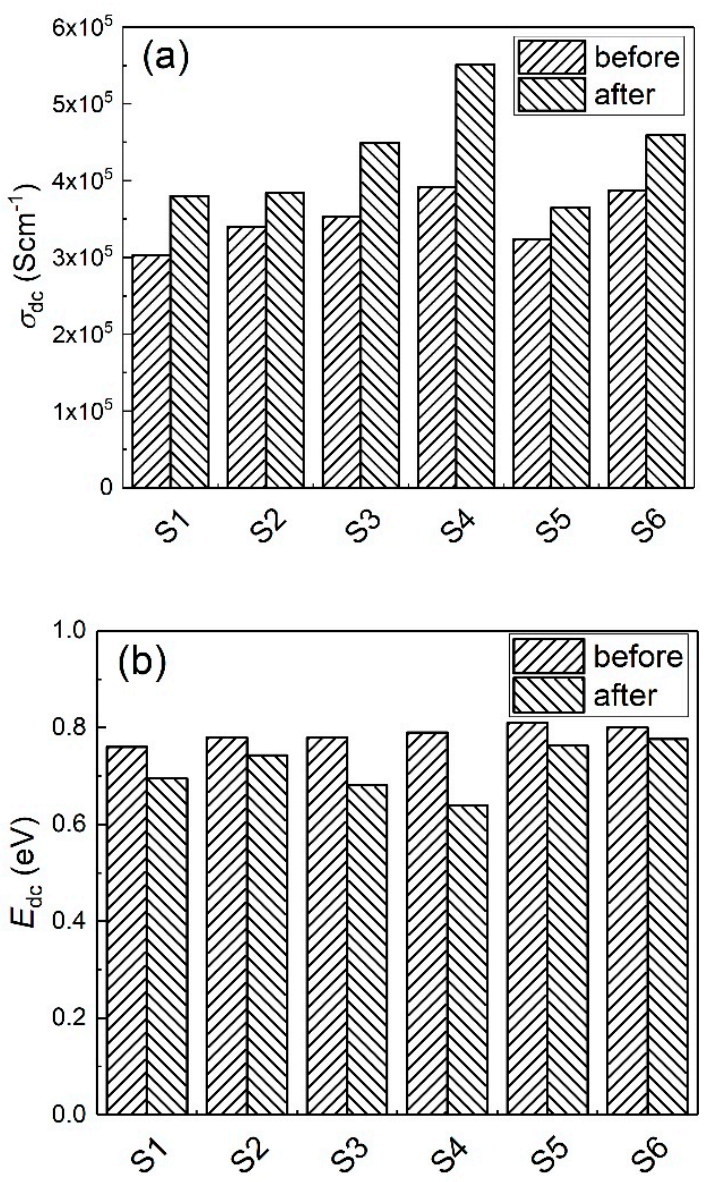

Figure 6. DC conductivities (a) and their activation energies (b) of S1-S6 before and after DC aging.

\subsection{Discussion}

DSB model was utilized to explained DC aging mechanism, as shown in Figure 7. Peak $A$ derives from electron relaxations between donor levels of $Z n_{i}$ and the conduction band in the depletion layers. Peak $B$ derives from similar processes of $V_{O}$. Peak $C$ and Peak $D$ have higher activation energies, and are related to electron emissions from different kinds of interfaces (boundaries). As leakage current density increased more in the negative direction than the positive direction, one could deduce that the forward-biased barrier height $\left(\Phi_{\mathrm{bF}}\right)$ decreased more and the reverse-biased barrier $\left(\Phi_{\mathrm{bR}}\right)$ decreased a bit during aging, i.e., $\Phi_{\mathrm{bF}}<\Phi_{\mathrm{bR}}<\Phi_{\mathrm{b} 0}$. In $\mathrm{ZnO}$ semiconductor, $\mathrm{Zn}_{\mathrm{i}}$ were too mobile to be stable at room temperature, with the migration energy about $0.57 \mathrm{eV}$ [31]. Oxygen, which could be adsorbed at the grain boundary and form localized acceptor states, played a key role in forming a potential barrier [32,33].

When the DC stress was applied, the depletion width $\left(w_{\mathrm{F}}\right)$ of the forward-biased barrier became narrow, while the reverse-biased barrier became wide, i.e., $w_{\mathrm{F}}<w_{0}<w_{R}$. As aging time increased, metastable cations, which were mainly $\mathrm{Zn}_{\mathrm{i}}$, migrated into grains for the forward-biased barrier. As to the reverse-biased barrier, metastable cations migrated to the grain boundary, some of which recombined with part of the localized states. At the grain boundary, metastable anions migrated from the forward-biased barrier to the reverse-biased one, which replenished the interface states in the reverse-biased barrier and was postulated being $\mathrm{O}_{a d}$ or its aliovalent species [34]. Finally, the barrier widths 
got narrower and satisfied $w_{\mathrm{R}}<w_{\mathrm{F}}<w_{0}$. Therefore, all parameters of loss peaks and DC conductivity due to the change of defect structure.

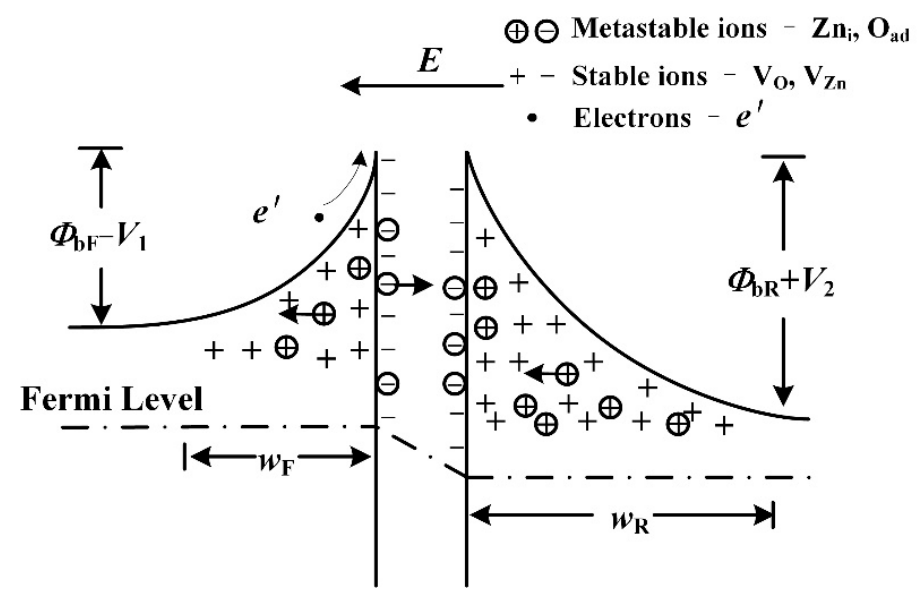

Figure 7. The schematic for ion migration based on the double Schottky barrier model.

The relation among the Schottky barrier height $\left(\Phi_{\mathrm{b}}\right)$, the density of the interface states $\left(N_{\mathrm{i}}\right)$ and the donor $\left(N_{\mathrm{d}}\right)$, and the depletion width $(w)$ satisfies the following expression [35]:

$$
\Phi_{\mathrm{b}}=\frac{e N_{\mathrm{d}} w^{2}}{2 \varepsilon_{\mathrm{r}} \varepsilon_{0}}=\frac{e N_{\mathrm{i}}^{2}}{2 \varepsilon_{\mathrm{r}} \varepsilon_{0} N_{\mathrm{d}}}
$$

where $e$ is the charge of an electron, $\varepsilon_{\mathrm{r}}$ the relative permittivity of $\mathrm{ZnO}$. Hence, the previous conclusion for the deformation of the DSB was deduced. Meanwhile, the complex defects related to Peak $C$ and Peak $D$ also changed due to the migration of oxygen ion in the $\mathrm{Bi}_{2} \mathrm{O}_{3}$-rich phases. The specific defects relative to Peak $D$ need further characterization. Besides, asymmetric conduction of $\mathrm{ZnO}$ varistors is also associated with nonuniform distribution of additives and grain sizes, especially due to ion redistributions after DC aging [36,37]. Conductivity, or say DSB, is a function of both voltage and temperature [38]. Ion distributions led to changes of the functions in both the positive and the negative directions. Establishing such a function is still one of the remaining challenges in the field [39].

\section{Conclusions}

DC aging mechanism was investigated based on $\mathrm{Co}_{2} \mathrm{O}_{3}$-doped $\mathrm{ZnO}$ varistors. During the aging process, the power loss decreased continuously except $\mathrm{S} 5$ with $\delta-\mathrm{Bi}_{2} \mathrm{O}_{3}$. After DC aging, breakdown field increased more in the positive direction than the negative direction, nonlinearity increased in the positive direction, whereas it decreased in the negative direction, and leakage current density increased more in the negative direction than the positive direction.

After DC aging, parameters of four relaxations were compared with the initial value, where the amplitudes of all relaxations changed. It was deduced that the migrations of $Z n_{i}$ and $\mathrm{O}_{\mathrm{ad}}$ changed the species of the interface states and then deformed the DSB. As a result, the forward-biased barrier height decreased more than the reverse-biased one.

Author Contributions: Conceptualization, X.Z. and H.S.; methodology, X.Z.; software, Z.H.; validation, X.Z., M.G. and Y.L.; formal analysis, Z.H.; investigation, X.Z.; resources, Z.H.; data curation, M.G.; writing—original draft preparation, M.G.; writing—review and editing, X.Z. and R.W.; visualization, Z.H.; supervision and project administration, H.S. and M.G. All authors have read and agreed to the published version of the manuscript.

Funding: This research was supported by The National Key R\&D Program of China (2018YFC0809400). 
Data Availability Statement: Data sharing not applicable. No new data were created or analyzed in this study. Data sharing is not applicable to this article.

Conflicts of Interest: The authors declare no conflict of interest.

\section{References}

1. He, J.L. Metal Oxide Varistors; TsingHua University Press: Beijing, China, 2019; pp. 1-4.

2. Kaufmann, B.; Billovits, T.; Kratzer, M.; Teichert, C.; Supancic, P. A modelling approach to describe the DC current-voltage behaviour of low-voltage zinc oxide varistors. Open Ceram. 2021, 6, 100113. [CrossRef]

3. Tsovilis, T.E.; Topcagic, Z. DC Overload Behavior of Low-Voltage Varistor-Based Surge Protective Devices. IEEE Trans. Power Deliv. 2020, 35, 2541-2543. [CrossRef]

4. Blatter, G.; Greuter, F. Carrier transport through grain boundaries in semiconductors. Phys. Rev. B 1986, 33, 3952-3966. [CrossRef] [PubMed]

5. Blatter, G.; Greuter, F. Electrical breakdown at semiconductor grain boundaries. Phys. Rev. B 1986, 34, 8555-8572. [CrossRef]

6. Gupta, T.K. Application of Zinc Oxide Varistors. J. Am. Ceram. Soc. 1990, 73, 1817-1840. [CrossRef]

7. Gupta, T.K.; Carlson, W.G. A grain-boundary defect model for instability/stability of a ZnO varistor. J. Mater. Sci. 1985, 20, 3487-3500. [CrossRef]

8. Eda, K.; Iga, A.; Matsuoka, M. Degradation mechanism of non-ohmic zinc oxide ceramics. J. Appl. Phys. 1980, 51, 2678-2684. [CrossRef]

9. Gupta, T.K.; Carlson, W.G. Barrier voltage and its effect on stability of ZnO varistor. J. Appl. Phys. 1982, 53, 7401-7409. [CrossRef]

10. Ramanachalam, M.S.; Rohatgi, A.; Schaffer, J.P.; Gupta, T.K. Characterization of ZnO varistor degradation using lifetime positron-annihilation spectroscopy. J. Appl. Phys. 1991, 69, 8380-8386. [CrossRef]

11. Yang, P.; Gomez, C.A.; Andrews, S.; Sorenson, J.D.; Chen, K.S. High-voltage surge protection by a varistor-filled air gap. J. Am. Ceram. Soc. 2021, 104, 3247-3259. [CrossRef]

12. Ohbuchi, Y.; Kawahara, T.; Okamoto, Y.; Morimoto, J. Characterization of interface states in degraded ZnO varistors. Jpn. J. Appl. Phys. 2002, 41, 190-196. [CrossRef]

13. Takahashi, K.; Miyoshi, T.; Maeda, K. Degradation of Zinc Oxide Varistors. MRS Proc. 1981, 5, 399. [CrossRef]

14. Ramirez, M.A.; Simoes, A.Z.; Bueno, P.R.; Márquez, M.A.; Orlandi, M.O.; Varela, J.A. Importance of oxygen atmosphere to recover the ZnO-based varistors properties. J. Mater. Sci. 2006, 41, 6221-6227. [CrossRef]

15. Mielcarek, W.; Gubanski, A.; Paściak, G.; Prociów, K.; Warycha, J.; Wrobel, J.M. The effect of bismuth oxide polymorph forms on degradation processes in $\mathrm{ZnO}$ varistors. Ceram. Int. 2013, 39, 8219-8226. [CrossRef]

16. Anderson, R.S. Lattice-vibration effects in the spectra of ZnO:Ni and ZnO:Co. Phys. Rev. 1967, 164, 398-405. [CrossRef]

17. Kim, E.D.; Kim, C.H.; Oh, M.H. Role and effect of $\mathrm{Co}_{2} \mathrm{O}_{3}$ additive on the upturn characteristics of ZnO varistors. J. Appl. Phys. 1985, 58, 3231-3235. [CrossRef]

18. Yano, Y.; Takai, Y.; Morooka, H. Interface states in ZnO varistor with Mn, Co and Cu impurities. J. Mater. Res. 1994, 9, 112-118. [CrossRef]

19. Guo, M.; Wang, Y.; Wu, K.N.; Zhang, L.; Zhao, X.; Lin, Y.; Li, J.Y. Revisiting the effects of $\mathrm{Co}_{2} \mathrm{O}_{3}$ on multiscale defect structures and relevant electrical properties in $\mathrm{ZnO}$ varistors. High Volt. 2020, 5, 241-248. [CrossRef]

20. Shuk, P.; Wiemhofer, H.D.; Guth, U.; Göpel, W.; Greenblatt, M. Oxide ion conducting solid electrolytes based on $\mathrm{Bi}_{2} \mathrm{O}_{3}$. Solid State Ion. 1996, 89, 179-196. [CrossRef]

21. Tanaka, T.; Baba, Y.; Tsujimoto, Y.; Tsukamoto, N. FDTD Electromagnetic and Thermal Simulation of a Metal Oxide Varistor Element Considering the Temperature Dependence of Its Resistivity. Electricity 2021, 2, 158-167. [CrossRef]

22. Staikos, E.T.; Tsovilis, T.E. Low-frequency response of low-voltage metal-oxide varistors used for telecommunication systems protection. In Proceedings of the 2020 IEEE International Conference on High Voltage Engineering and Application (ICHVE), Beijing, China, 6-10 September 2020; pp. 1-4.

23. Huang, Y.; Wu, K.; Xing, Z.; Zhang, C.; Hu, X.; Guo, P.; Li, J.Y. Understanding the validity of impedance and modulus spectroscopy on exploring electrical heterogeneity in dielectric ceramics. J. Appl. Phys. 2019, 125, 084103. [CrossRef]

24. Zhao, X.; Shi, W.D.; Zhang, B.Y.; Guo, M.; Shen, H.B. Relaxation peaks of ZnO varistors and their correlations with electrical properties. Jpn. J. Appl. Phys. 2021, 60, 031006. [CrossRef]

25. Cole, K.S.; Cole, R.H. Dispersion and absorption in dielectrics I. alternating current characteristics. J. Chem. Phys. 1941, 9, 341-351. [CrossRef]

26. Cheng, P.; Li, S.; Zhang, L.; Li, J.Y. Characterization of intrinsic donor defects in ZnO ceramics by dielectric spectroscopy. Appl. Phys. Lett. 2008, 93, 012902. [CrossRef]

27. Zhao, X.; Li, J.Y.; Li, H.; Li, S.T. Intrinsic and extrinsic defect relaxation behavior of ZnO ceramics. J. Appl. Phys. 2012, 111, 6132. [CrossRef]

28. West, A.R.; Andres-Verges, M. Impedance and Modulus Spectroscopy of ZnO Varistors. J. Electroceramics 1997, 1, 125-132. [CrossRef]

29. Huang, Y.; Wu, K.; Tang, Z.; Xin, L.; Zhang, L.; Li, J. Investigation of electrical inhomogeneity in ZnO varistor ceramics based on electronic relaxations. Ceram. Int. 2019, 45, 1110-1114. [CrossRef] 
30. He, J.; Li, S.; Lin, J.; Zhang, L.; Feng, K.; Zhang, L.; Li, J. Reverse manipulation of intrinsic point defects in ZnO-based varistor ceramics through $\mathrm{Zr}$-stabilized high ionic conducting $\beta_{\mathrm{III}}-\mathrm{Bi}_{2} \mathrm{O}_{3}$ intergranular phase. J. Eur. Ceram. Soc. 2018, 38, 1614-1620. [CrossRef]

31. Janotti, A.; Van de Walle, C.G. Fundamentals of zinc oxide as a semiconductor. Rep. Prog. Phys. 2009, 72, 126501. [CrossRef]

32. Stucki, F.; Greuter, F. Key role of oxygen at zinc oxide varistor grain boundaries. Appl. Phys. Lett. 1990, 57, 446-448. [CrossRef]

33. Bueno, P.R.; Leite, E.R.; Oliveira, M.M.; Orlandi, M.O.; Longo, E. Role of oxygen at the grain boundary of metal oxide varistors: A potential barrier formation mechanism. Appl. Phys. Lett. 2001, 79, 48-50. [CrossRef]

34. Eda, K. Zinc oxide varistors. IEEE Electr. Insul. Mag. 1989, 5, 28-30. [CrossRef]

35. Emtage, P.R. The physics of zinc oxide varistors. J. Appl. Phys. 1977, 48, 4372-4384. [CrossRef]

36. Chiang, Y.; Kingery, W.D.; Levinson, L.M. Compositional changes adjacent to grain boundaries during electrical degradation of a ZnO varistor. J. Appl. Phys. 1982, 53, 1765-1768. [CrossRef]

37. Topcagic, Z.; Tsovilis, T.E. Varistor Electrical Properties: Microstructural Effects. In Encyclopedia of Materials: Technical Ceramics and Glasses; Pomeroy, E.M., Ed.; Elsevier: Oxford, UK, 2021; pp. 254-271.

38. Zhou, Q.; Yang, H.; Huang, X.; Wang, M.; Ren, X. Numerical modelling of MOV with Voronoi network and finite element method. IET High Volt. 2021, 1-8. [CrossRef]

39. Greuter, F. ZnO Varistors: From Grain Boundaries to Power Applications. In Oxide Electronics; Wiley: Hoboken, NJ, USA, 2021. 